\title{
THERMOELASTIC PROBLEMS OF FUNCTIONALLY GRADED MULTILAYERED INCOMPRESSIBLE SPHERICAL BODIES
}

\author{
András Havellant \\ Student, University of Miskolc, Institute of Applied Mechanics \\ 3515 Miskolc, Miskolc-Egyetemváros, e-mail: havandris@gmail.com \\ László Kiss \\ Student, University of Miskolc, Institute of Applied Mechanics \\ 3515 Miskolc, Miskolc-Egyetemváros, e-mail: laszlokiss706@gmail.com
}

\begin{abstract}
The main objective of this paper is to determine the stresses and displacements in radially graded multilayered spherical bodies made from incompressible functionally graded materials. The material properties are arbitrary functions of the radial coordinate. The body is subjected to constant pressure and a temperature field, which is an arbitrary function of the radial coordinate. An analytical method is presented to tackle these problems then compared to solutions coming from finite element simulations.
\end{abstract}

Keywords: FGM, incompressible, sphere, multilayered

\section{Introduction}

In recent decades layered composite and functionally graded materials (FGMs) have been widely used in numerous engineering applications due to their excellent material behavior. These materials have improved thermal resistance and mechanical properties. The smooth transition between the components decreases the chance of cracking and debonding under thermal and mechanical loads. A lot of papers and books deal with the mechanics of these advanced materials. Books by Boley and Weiner [1], Lekhnitskii [2] and Lomakin [3] give solutions to many linearly elastic problem for nonhomogeneous bodies, furthermore there are lots of papers, such as [4-11] that tackle the thermomechanical problems of different simple functionally graded and multilayered components (e.g. beams or disks) from different aspects. Several papers can be found in the topic of functionally graded spherical bodies. Lutz and Zimmerman in [12] and [13] give analytical solutions for the stress and displacement fields within functionally graded spherical bodies and circular cylinders. Papers [14] and [15] present analytical solutions to obtain the radial, tangential and effective stresses within thick spherical pressure vessels made of FGMs subjected to axisymmetric simple thermomechanical loads. The material properties are assumed to be graded in the radial direction based on the power-law function of the radial coordinate but the Poisson ratio has constant value. Paper [16] gives solutions for thick radially graded cylinders and spherical pressure vessels where the material properties of FGMs is assumed to be exponential function form. In paper [17] a general thermoelastic analysis of one-dimensional steady-state thermal stresses in a hollow thick cylinder made of functionally graded material is presented. Kar and Kanoria [18] dealt with the determination of thermo-elastic interaction due to a step input of temperature on the boundaries of a radially graded orthotropic hollow sphere in 
the context of linear theories of generalized thermo-elasticity using a vector-matrix formalism and eigenvalue solution approach. Bich and Tung [19] presented an analytical approach to investigate the non-linear axisymmetric response of functionally graded shallow spherical shells subjected to constant external pressure incorporating the effects of temperature field and imperfections. Gönczi [20] derived an analytical method to calculate the stresses in multilayered spheres, then used this method to tackle a general problem of temperature dependent radially graded spherical pressure vessels. Ye et. al [21] investigated the free vibration of laminated functionally graded spherical shells with general boundary conditions and arbitrary geometric parameters with power law distribution based on three-dimension linearized shell theory and Rayleigh-Ritz method. Paper [22] studied the elastic - perfectly plastic thermal stress analysis of radially graded spheres and the material properties are power functions of the radial coordinate. Nematolli et. al. [23] presented an analytical solution of thermal and mechanical displacements and stresses for a thick-walled rotating spherical pressure vessel made of functionally graded materials in a uniform magnetic field assuming power law distribution along the thickness. In paper [24] a numerical algorithm is developed to describe the thermoelastic wave in multilayered spherical shells with functionally graded layers under thermal boundary conditions based on LordShulman generalized coupled thermoelasticity theory. Viola et. al. [25] studied the static behavior of functionally graded spherical shells and panels subjected to uniform loadings, the material properties are graded in the thickness direction according to a four- parameter power law, and a GDQ numerical technique is used to solve the system of differential equations. Arefi and Zenkour [26] investigated the problems of functionally graded spherical pressure vessels using non-linear shell theory and Adomians decomposition method. In paper [27] a closed form solution was developed for spheres, in which the functions of the material properties - except the Poisson's ratio - are power law functions. Then a multilayered approach was used with Boussinesq displacement potentials to deal with the optimization problem of hollow spheres. In [28] a closed form analytical solution is presented for special thermoelastoplastic problems of thick-walled spheres. Akinlabi et. al. [29] developed a thermoelastopalstic method to calculate the stresses and displacements in functionally graded spheres after thermal treatment. In [30] an analytical method is presented to calculate the thermal stresses in incompressible radially graded spheres. Paper [31] uses perturbation technique and solves the shell problem in case of temperature dependent material properties.

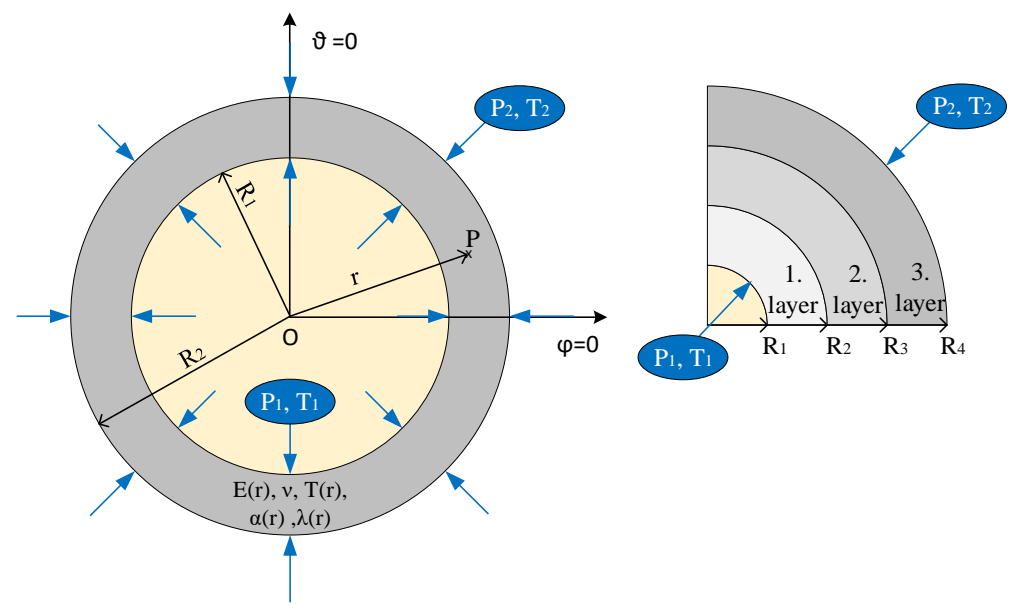

Figure 1. The sketch of the problem. 
A multilayered incompressible radially graded hollow sphere is considered. The sketch of the problem can be seen in Fig. 1. The number of layers is denoted by $N$, the material properties are arbitrary functions of the radial coordinate. Spherical coordinate system will be used. Our aim is to determine the analytical solution for the stress and displacement fields within the radially graded multilayered sphere.

\section{Governing equations}

The Poisson's ratio of incompressible materials is $v=0.5$ thus the Young modulus and the shear modulus have the relation $E=3 G$. This problem is an axisymmetric problem where the displacement field is $\mathbf{u}=u(r) \mathbf{e}_{r}$ and the kinematic equations are [1-3, 32]

$$
\varepsilon_{r}(r)=\frac{\mathrm{d} u(r)}{\mathrm{d} r}, \quad \varepsilon_{\varphi}(r)=\varepsilon_{\vartheta}(r)=\frac{u(r)}{r} .
$$

The normal strains can be calculated as the sum of its mechanical and thermal components, furthermore the constitutive law can be expressed as

$$
\begin{gathered}
\varepsilon_{r}(r)=\frac{\sigma_{r}(r)-\sigma_{\varphi}(r)}{E(r)}+\alpha(r) T(r), \\
\varepsilon_{\varphi}(r)=\frac{-\sigma_{r}(r)+\sigma_{\varphi}(r)}{2 E(r)}+\alpha(r) T(r),
\end{gathered}
$$

where $T(r)$ denotes the temperature field, $\sigma_{r}, \sigma_{\varphi}, \sigma_{\vartheta}$ are the radial and hoop (or tangential normal) stresses, $\varepsilon_{r}, \varepsilon_{\varphi}, \varepsilon_{\vartheta}$ denote the normal strain coordinates of the strain tensor. The trace of the strain tensor yields to

$$
\varepsilon=\varepsilon_{r}+\varepsilon_{\varphi}+\varepsilon_{\vartheta}=\varepsilon_{r}+2 \varepsilon_{\varphi}=3 \alpha T .
$$

The combination of Eqs. (1-4) leads to the following differential equations

$$
\varepsilon(r)=\frac{d u(r)}{d r}+2 \frac{u(r)}{r}=\frac{1}{r^{2}} \frac{d}{d r}\left(u r^{2}\right) .
$$

The solution for the radial displacement coordinate can be given as

$$
u(r)=\frac{3 \int_{R_{1}}^{r} \rho^{2} \alpha(\rho) T(\rho) d \rho}{r^{2}}+\frac{A_{1}}{r^{2}} .
$$

The previous expression can be simplified by the following notation

$$
V_{1}(r)=\int_{R_{1}}^{r} \rho^{2} \alpha(\rho) T(\rho) d \rho, u(r)=3 \frac{V_{1}(r)}{r^{2}}+\frac{A_{1}}{r^{2}} .
$$

In spherical bodies the equilibrium equation has the following form 


$$
\frac{d \sigma_{r}}{d r}+2 \frac{\sigma_{r}-\sigma_{\varphi}}{r}+b_{r}=0
$$

where $b_{r}$ denotes the radial body force. The stresses in incompressible materials can be expressed as $[1,32]$

$$
\begin{gathered}
\sigma_{r}=2 G \varepsilon_{r}^{m}+\sigma_{0}=\frac{2}{3} E \varepsilon_{r}^{m}+\sigma_{0}, \\
\sigma_{\varphi}=\sigma_{\vartheta}=2 G \varepsilon_{\varphi}^{m}+\sigma_{0}=\frac{2}{3} E \varepsilon_{\varphi}^{m}+\sigma_{0},
\end{gathered}
$$

where

$$
\sigma_{0}=\frac{\sigma_{r}+\sigma_{\varphi}+\sigma_{\vartheta}}{3}=\frac{\sigma_{r}+2 \sigma_{\varphi}}{3} .
$$

The combination of eqs. (8-11) leads to

$$
\begin{gathered}
\frac{d \sigma_{r}}{d r}=4 A_{1} \frac{E(r)}{r^{4}}+12 \frac{E(r) F_{1}(r)}{r^{4}}-4 \frac{E(r) \alpha(r) T(r)}{r}-b_{r}(r), \\
\sigma_{r}(r)=4 C_{1} \int_{R_{1}}^{r} \frac{E(\rho)}{\rho^{4}} \mathrm{~d} \rho+12 \int_{R_{1}}^{r} \frac{E(\rho) F_{1}(\rho)}{\rho^{4}} \mathrm{~d} \rho-4 \int_{R_{1}}^{r} \frac{E(\rho) \alpha(\rho) T(\rho)}{\rho} \mathrm{d} \rho-\int_{R_{1}}^{r} b_{r}(\rho) \mathrm{d} \rho+A_{2} .
\end{gathered}
$$

The unknown constants of integrations can be calculated from the boundary conditions. When the pressures at the inner and outer boundary surfaces are given we have

$$
p_{1}=-\sigma_{r}\left(R_{1}\right), p_{2}=-\sigma_{r}\left(R_{2}\right) .
$$

When mixed boundary conditions with the radial displacement of the outer boundary is given (which means that there is a rigid casing around the spherical body):

$$
u_{\text {presc }}=u\left(R_{2}\right), p_{1}=-\sigma_{r}\left(R_{1}\right) .
$$

The tangential normal stresses can be expressed as the combination of the previous equations:

$$
\sigma_{\varphi}(r)=\frac{1}{2} r\left(\frac{d \sigma_{r}}{d r}+b_{r}\right)+\sigma_{r}
$$

\section{Numerical examples}

In the numerical example the spherical body is divided into 3 radially graded layers (where the thickness of every layer is $0.03 \mathrm{~m}$ ). Each layer has different material properties, furthermore the temperature field is given. These properties and fields are described with the following functions: 


$$
\begin{gathered}
\alpha_{1}=\alpha_{01}\left(\frac{r}{R_{1}}\right)^{m_{1}}, \alpha_{2}=\alpha_{02} e^{r m}, \alpha_{3}=\alpha_{03} \sin \left(m_{4} r^{2}\right), \\
E_{1}=E_{01}\left(\frac{r}{R_{1}}\right)^{m_{1}}, E_{2}=E_{0} e^{r m_{3}}, E_{3}=E_{03} \sin \left(m_{4} r^{2}\right), \\
T(r)=-550+\frac{200}{r^{2}} .
\end{gathered}
$$

The following data will be used for the computations:

$$
\begin{aligned}
& R_{1}=0.5 \mathrm{~m}, R_{2}=0.59 \mathrm{~m}, \alpha_{01}=1.2 \cdot 10^{-6} \frac{1}{\mathrm{~K}}, \alpha_{02}=3.6 \cdot 10^{-6} \frac{1}{\mathrm{~K}}, \alpha_{03}=1.2 \cdot 10^{-6} \frac{1}{\mathrm{~K}}, E_{01}=210 \mathrm{GPa} \\
& E_{02}=600 \mathrm{GPa}, E_{03}=210 \mathrm{GPa}, m_{1}=2, m_{3}=-2.1, m_{4}=1.5, p_{1}=50 \mathrm{MPa}, p_{2}=5 \mathrm{MPa} .
\end{aligned}
$$

Figures 2, 3 and 4 depict comparisons of the results from the analytical (calculated in MAPLE) and finite element simulations (in Abaqus, [33]). In the finite element simulations, the functionally graded sphere is modelled as a multilayer body with $N=9$ and $N=18$ homogeneous spherical layers. Table 1 shows the exact results of each calculation at specified distances and the relative errors.

$\mathrm{U}$ displacement along thickness

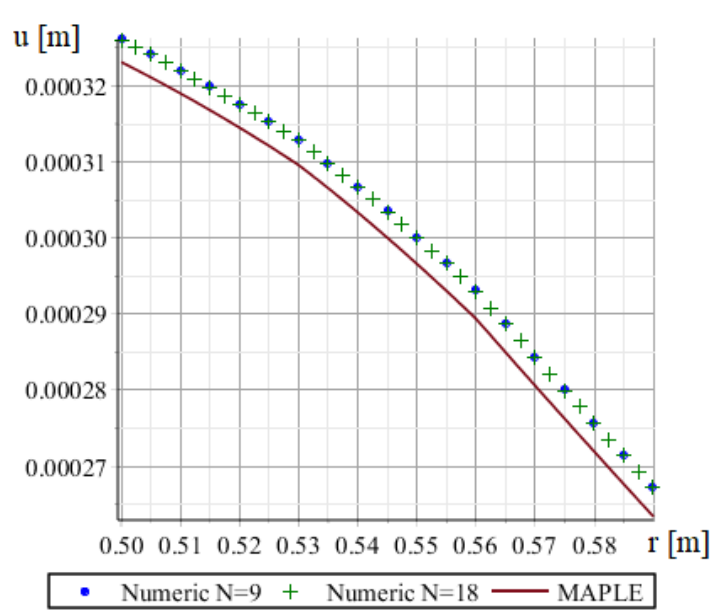

Figure 2. Comparison of the displacements.
Radial normal stress along thickness

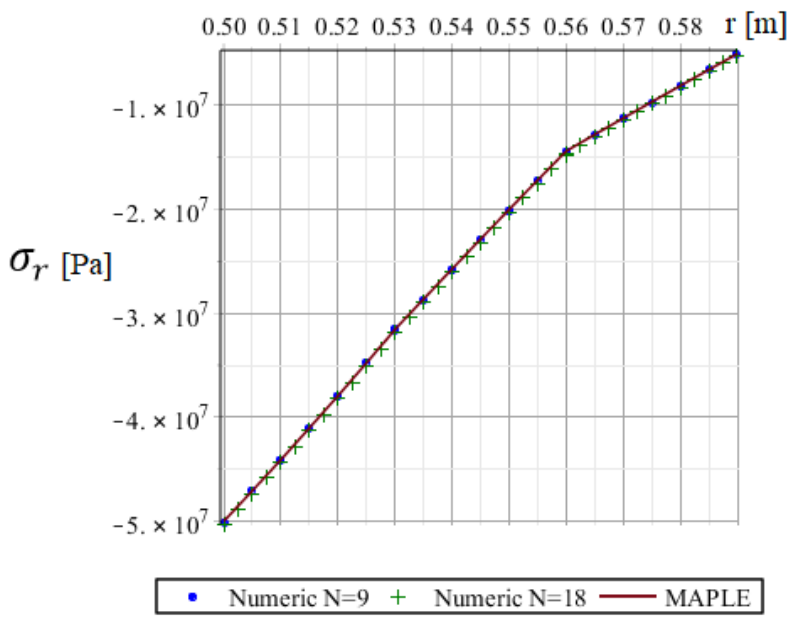

Figure 3. Comparison of the radial stresses. 


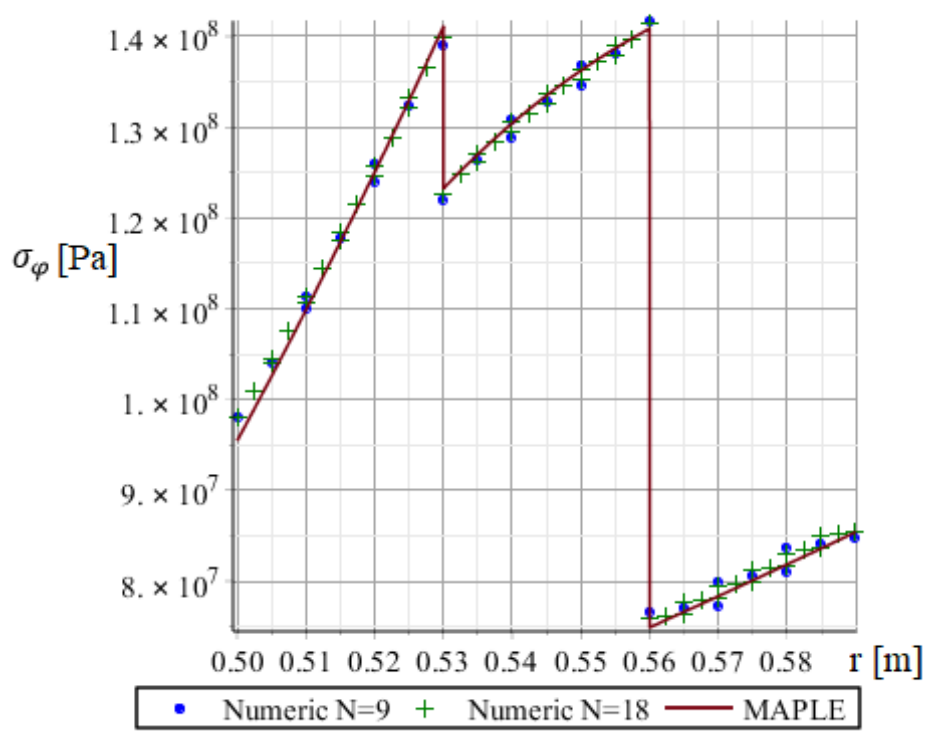

Figure 4. Comparison of the tangential stresses.

Table 1. Exact values and relative errors.

\begin{tabular}{|l|c|c|c|c|c|c|}
\hline Displacement $(\mathrm{m})$ & $\mathrm{r}=0.5$ & $\mathrm{r}=0.52$ & $\mathrm{r}=0.54$ & $\mathrm{r}=0.56$ & $\mathrm{r}=0.58$ & $\mathrm{r}=0.59$ \\
\hline MAPLE & $3,23 \mathrm{E}-04$ & $3,15 \mathrm{E}-04$ & $3,03 \mathrm{E}-04$ & $2,89 \mathrm{E}-04$ & $2,72 \mathrm{E}-04$ & $2,63 \mathrm{E}-04$ \\
\hline Numeric N=18 & $3,26 \mathrm{E}-04$ & $3,18 \mathrm{E}-04$ & $3,07 \mathrm{E}-04$ & $2,93 \mathrm{E}-04$ & $2,76 \mathrm{E}-04$ & $2,67 \mathrm{E}-04$ \\
\hline Numeric N=9 & $3,26 \mathrm{E}-04$ & $3,18 \mathrm{E}-04$ & $3,07 \mathrm{E}-04$ & $2,93 \mathrm{E}-04$ & $2,76 \mathrm{E}-04$ & $2,67 \mathrm{E}-04$ \\
\hline Relative error N=18 (\%) & $-0,91$ & $-0,97$ & $-1,10$ & $-1,26$ & $-1,40$ & $-1,46$ \\
\hline Relative error N=9 (\%) & $-0,93$ & $-0,99$ & $-1,12$ & $-1,28$ & $-1,41$ & $-1,47$ \\
\hline
\end{tabular}

\begin{tabular}{|l|c|c|c|c|c|c|}
\hline Radial normal stress $(\mathrm{Pa})$ & $\mathrm{r}=0.5$ & $\mathrm{r}=0.52$ & $\mathrm{r}=0.54$ & $\mathrm{r}=0.56$ & $\mathrm{r}=0.58$ & $\mathrm{r}=0.59$ \\
\hline MAPLE & $-5,00 \mathrm{E}+07$ & $-3,79 \mathrm{E}+07$ & $-2,57 \mathrm{E}+07$ & $-1,44 \mathrm{E}+07$ & $-8,08 \mathrm{E}+06$ & $-5,00 \mathrm{E}+06$ \\
\hline Numeric N=18 & $-5,03 \mathrm{E}+07$ & $-3,82 \mathrm{E}+07$ & $-2,60 \mathrm{E}+07$ & $-1,46 \mathrm{E}+07$ & $-8,29 \mathrm{E}+06$ & $-5,19 \mathrm{E}+06$ \\
\hline Numeric N=9 & $-5,01 \mathrm{E}+07$ & $-3,80 \mathrm{E}+07$ & $-2,58 \mathrm{E}+07$ & $-1,44 \mathrm{E}+07$ & $-8,13 \mathrm{E}+06$ & $-5,03 \mathrm{E}+06$ \\
\hline Relative error N=18 (\%) & $-0,62$ & $-0,75$ & $-1,22$ & $-1,55$ & $-2,51$ & $-3,73$ \\
\hline Relative error $\mathrm{N}=9(\%)$ & $-0,17$ & $-0,09$ & $-0,26$ & $-0,49$ & $-0,61$ & $-0,67$ \\
\hline
\end{tabular}

\begin{tabular}{|l|c|c|c|c|c|c|}
\hline Tangential normal stress $(\mathrm{Pa})$ & $\mathrm{r}=0.5$ & $\mathrm{r}=0.52$ & $\mathrm{r}=0.54$ & $\mathrm{r}=0.56$ & $\mathrm{r}=0.58$ & $\mathrm{r}=0.59$ \\
\hline MAPLE & $9,54 \mathrm{E}+07$ & $1,25 \mathrm{E}+08$ & $1,30 \mathrm{E}+08$ & $7,49 \mathrm{E}+07$ & $8,19 \mathrm{E}+07$ & $8,54 \mathrm{E}+07$ \\
\hline Numeric $\mathrm{N}=18$ & $9,80 \mathrm{E}+07$ & $1,26 \mathrm{E}+08$ & $1,30 \mathrm{E}+08$ & $7,60 \mathrm{E}+07$ & $8,31 \mathrm{E}+07$ & $8,55 \mathrm{E}+07$ \\
\hline Numeric N=9 & $9,80 \mathrm{E}+07$ & $1,26 \mathrm{E}+08$ & $1,29 \mathrm{E}+08$ & $7,65 \mathrm{E}+07$ & $8,36 \mathrm{E}+07$ & $8,47 \mathrm{E}+07$ \\
\hline Relative error $\mathrm{N}=18(\%)$ & $-2,70$ & $-0,48$ & 0,67 & $-1,39$ & $-1,51$ & $-0,07$ \\
\hline Relative error $\mathrm{N}=9(\%)$ & $-2,64$ & $-0,66$ & 1,22 & $-2,09$ & $-2,16$ & 0,87 \\
\hline
\end{tabular}




\section{Summary}

An analytical method was presented to tackle the thermoelastic problem of functionally graded incompressible hollow spheres subjected to combined mechanical and thermal loads. The material properties and the temperature field were arbitrary functions of the radial coordinate. The stress and displacement fields were calculated then compared to results coming from finite element simulations. The results are in good agreement.

\section{References}

[1] Boley, B. A., Weiner, J. H.: Theory of Thermal Stresses. John Wiley \& Sons Inc., New York, 1960.

[2] Lekhnitskii, S. G.: Theory of Elasticity of an Anisotropic Body. Mir Publishers, Moscow, 1981.

[3] Lomakin, V. A.: Theory of Nonhomogeneous Elastic Bodies. MGU, Moscow, 1976.

[4] Kiss, L. P. Nonlinear stability analysis of FGM shallow arches under an arbitrary concentrated radial force. International Journal of Mechanics and Materials in Design 2020, 16(1):91-108. https://doi.org/10.1007/s10999-019-09460-2

[5] Sadowski, T., Birsan, M., Pietras, D.: Multilayered and FGM structural elements under mechanical and thermal loads. Part I: Comparison of finite elements and analytical models. Archives of Civil and Mechanical Engineering 2015, 15(4):1180-1192. https://doi.org/10.1016/j.acme.2014.09.004

[6] Gönczi, D.: Analysis of curved bimetallic beam. Journal of Computational and Applied Mechanics 2019, 41(1-2):41-51. https://doi.org/10.32973/jcam.2019.003

[7] Pen, X., Li, X.: Thermoelastic analysis of functionally graded annulus with arbitrary gradient, Applied Mathematics and Mechanics (English Edition) 2009, 30(10):1211-1220. https://doi.org/10.1007/s10483-009-1001-7

[8] Sondhi, L., Thawait, A. K., Sanyal, S., Bhowmick, S.: Stress and Deformation Analysis of Variable Thickness Clamped Rotating Disk of Functionally Graded Orthotropic Material. $\begin{array}{llll}\text { Materials } \quad \text { Today: } & \text { Proceedings }\end{array}$ https://doi.org/10.1016/j.matpr.2019.07.412

[9] Hua, Y-J., Zhoua, H., Zhub, W., Zhu, J.: A thermally-coupled elastic large-deformation model of a multilayered functionally graded material curved beam. Composite structures 2020, 244:112241. https://doi.org/10.1016/j.compstruct.2020.112241

[10] Gönczi, D.: Analysis of Rotating Functionally Graded Disks with Arbitrary Material Properties. Acta Technica Corviniensis - Bulletin of Engineering 2018, 11:1-6.

[11] Allam, M. N. M., Tantawy, R., Zenkour, A. M.: Thermoelastic stresses in functionally graded rotating annular disks with variable thickness. Journal of Theoretical and Applied Mechanics 2019, 56(4):1029-1041. https://doi.org/10.15632/jtam-pl.56.4.1029

[12] Lutz, M. P., Zimmerman, R. W.: Thermal stresses and effective thermal expansion coefficient of a functionally graded sphere. Journal of Thermal Stress 1996, 19:39-54. https://doi.org/10.1080/01495739608946159

[13] Zimmerman, R. W., Lutz, M. P.: Thermal stresses and thermal expansion in an uniformly heated functionally graded cylinder. Journal of Thermal Stress 1999, 22:77-178. https://doi.org/10.1080/014957399280959 
[14] Nayak, P., Mondal, S. C., Nandi, A.: Stress, strain and displacement of a functionally graded thick spherical vessel. International Journal of Engineering Science and Technology 2011, 3(4):2660-2671.

[15] Bayat, Y., Ghannad, M., Torabi, H.: Analytical and numerical analysis for the FGM thick sphere under combined pressure and temperature loading. Archive of Applied Mechanics 2011, 10:229-242. https://doi.org/10.1007/s00419-011-0552-x

[16] Chen, Y. Z., Lin, X. Y.: Elastic analysis for thick cylinders and spherical pressure vessels made of functionally graded materials. Computational Materials Science 2008, 44(2):581-587. https://doi.org/10.1016/j.commatsci.2008.04.018

[17] Jabbari, M., Sohrabpour, S., Eslami, M. R.: Mechanical and thermal stresses in a functionally graded hollow cylinder due to radially symmetric loads. International Journal of Pressure Vessels and Piping 2002, 79(7):493-497. https://doi.org/10.1016/S0308-0161(02)00043-1

[18] Kar, A., Kanoria, M.: Generalized thermoelastic functionally graded orthotropic hollow sphere under thermal shock with three-phase-lag effect. European Journal of Mechanics, A/Solids, 2009, 28(4):757-767. https://doi.org/10.1016/j.euromechsol.2009.01.003

[19] Bich, D. H., Tung, H. V.: Non-linear axisymmetric response of functionally graded shallow spherical shells under uniform external pressure including temperature effects. International Journal of Non-Linear Mechanics 2011, 46(9):1195-1204. https://doi.org/10.1016/j.ijnonlinmec.2011.05.015

[20] Gönczi, D.: Thermoelastic analysis of thick-walled functionally graded spherical pressure vessels with temperature-dependent material properties. Journal of Computational and Applied Mechanics 2017, 12(2):109-125. https://doi.org/10.32973/jcam.2017.008

[21] Ye, T., Jin, G., Su, Z.: Three-dimensional vibration analysis of laminated functionally graded spherical shells with general boundary conditions. Composite structures 2014, 116,:571-588. https://doi.org/10.1016/j.compstruct.2014.05.046

[22] Sadeghian, M., Toussi, H. E.: Axisymmetric yielding of functionally graded spherical vessel under thermo-mechanical loading. Computational Material Science 2011, 50(3):975-981. https://doi.org/10.1016/j.commatsci.2010.10.036

[23] Nematollahi, M. A., Dini, A., Hosseini, M.: Thermo-magnetic analysis of thick-walled spherical pressure vessels made of functionally graded materials. Applied Mathematics and Mechanics 2019, 40:751-766. https://doi.org/10.1007/s10483-019-2489-9

[24] Heydarpour, Y., Malekzadeh, P.: Thermoelastic Analysis of Multilayered FG Spherical Shells Based on Lord-Shulman Theory. Iranian Journal of Science and Technology, Transactions of Mechanical Engineering 2019, 43:845-867. https://doi.org/10.1007/s40997-018-0199-0

[25] Viola, E., Rossetti, L., Fantuzzi, N., Tornabene, F.: Generalized stress-strain recovery formulation applied to functionally graded spherical shells and panels under static loading. Composite Structures 2016, 156:145-164. https://doi.org/10.1016/j.compstruct.2015.12.060

[26] Arefi, M., Zenkour, A. M.: Nonlinear and linear thermo-elastic analyses of a functionally graded spherical shell using the Lagrange strain tensor. Smart Structures and systems, 19(1), pp. pp. 33-38, 2017. https://doi.org/10.12989/sss.2017.19.1.033

[27] Zheng, C., Li, X., Mi, C.: Reducing stress concentrations in unidirectionally tensioned thickwalled spheres through embedding a functionally graded reinforcement. International Journal of Mechanical Sciences 2019, 152:257-267. https://doi.org/10.1016/j.ijmecsci.2018.12.055 
[28] Parvizi, A., Alikarami, S., Asgari, M.: Exact solution for thermoelastoplastic behavior of thickwalled functionally graded sphere under combined pressure and temperature gradient loading. Journal of Thermal Stresses 2016, 39(9):1152-1170. https://doi.org/10.1080/01495739.2016.1188614

[29] Akinlabi, E. T., Dats, E. P., Murashkin, E. V.: Thermoelasticplastic deformation of a functionally graded spherical layer. Journal of Physics: Conference Series 2020, 1474:012002. https://doi.org/10.1088/1742-6596/1474/1/012002

[30] Gönczi, D.: Thermoelastic analysis of functionally graded incompressible spherical bodies. Annals of Faculty of Engineering Hunedoara - International Journal of Engineering 2016, 14(2):103-106.

[31] Moosaie, A., Panahi-Kalus, H.: Thermal stresses in an incompressible FGM spherical shell with temperature-dependent material properties. Thin-Walled Structures 2017, 120:215-224. https://doi.org/10.1016/j.tws.2017.09.005

[32] Nowinski, I. L.: Theory of Thermoelasticity with Applications. Sythoff and Noordhoff, Alpen aan den Rijn, 1978. https://doi.org/10.1007/978-94-009-9929-9

[33] Abaqus User Manual. 2020. 